\title{
The Quality Of Life Of Post-Stroke Patients At The Nerve Clinic Of Ulin General Hospital In Banjarmasin
}

\author{
Mohammad Basit ${ }^{1 *}$ \\ ${ }^{1}$ STIKES Sari Mulia Banjarmasin \\ mohammad_basit@stikessarimulia.ac.id \\ Dini Rahmayani ${ }^{1}$ \\ ${ }^{1}$ STIKES Sari Mulia Banjarmasin \\ dini_rahmayani@stikessarimulia.ac.id
}

\begin{abstract}
Objective: Post-Stroke Clients will experience psychological disorders. Psychological disorders occur because of inability to undergo daily activities, as usual, so often appear on the client is unstable emotions and will impact on the quality life of post-stroke patients. A description of the psychological disorders shown by an outpatient post-stroke client at The Nerve Clinic of Ulin General Hospital Banjarmasin varies greatly, depending on how the family provides care and attention while at home.

Methods: The research design used qualitative descriptive explorative approach. Sampling technique in this research is using judgment sampling where a person becomes a sample because they have "information rich".

Result: Nursing care at home Post-Stroke client hasn't done well, family role and support for PostStroke clients is good enough. Quality of life Post-Stroke mostly has a good quality of life.

Conclusion: Discharge planning activities in the hospital need to be maximized. Need to increase family support for clients of post-stroke, both in the form of attention and affection. Helps to carry out daily activities and support in terms of information can raise to confidence and high motivation of clients to undergo regular treatment. It can improve self-concept to the direction of high quality of life. In providing nursing care clients of post-stroke, the family is expected to be involved in the counseling and theologian because post-stroke patients are vulnerable to psychological decline.
\end{abstract}

Keywords: Patient, Post-Stroke, Quality of life

\section{INTRODUCTION}

Stroke is a clinical manifestation of cerebral functional disorders, both focal, regional and physical changes that usually occur rapidly, lasting 24 hours or more, can cause deaths caused by brain blood circulation (World Health Organization). Signs of symptoms of stroke patients are partial paralysis of motion, loss of swallowing ability, cognitive impairment and psychological disorders [1]. This will affect the patient's ability to perform daily activities such as eating, dressing, personal hygiene, and others. While changes in cognitive are indicated by the inability to make decisions, memory and judgment damage, disorientation, misperception, decreased attention span, and logical thinking difficulties. If not handled properly, interference.

\section{METHODS}

The research design used in this research use descriptive explorative qualitative approach. Population in this research is Patient 
of Stroke at Ulin Hospital Banjarmasin. While the sampling technique in the research is by using Judgment Sampling where a person becomes a sample because they have "information rich". This research was conducted for 1 month in

Room Poly Neurology Ulin Hospital Banjarmasin South Kalimantan.

This research uses data analysis technique model Miles and Huberman. Activity in this qualitative data analysis will be done interactively and lasted continuously until complete so that the data is saturated. The process of analyzing the data will begin by reviewing all available data from various sources, ie in-depth interviews. The data is then analyzed through three components that include data reduction, data presentation, and conclusion drawing/verification [2].

\section{RESULT}

\section{a. Quality of Life of Post-Stroke Patients}

Based on the results of qualitative research to find out how the quality of life of patients post-stroke obtained the majority of respondents in general quality of life poststroke patients low health-related. Low quality of life-related to health is due to problems that occur in post-stroke patients [3]. Post-stroke problematics are generally paralyzed on one side of the body (hemiparesis / hemiplegia), paralyzed on one side of the face, weak muscle tone or stiffness, decreased / loss of taste, disturbance of the field of view, Language disorders, perceptual disorders and mental stroke disorders including cognitive and memory functions. Said that stroke resulted in physical disability, emotion, and social equality. It has a major effect on the quality of life related to health in stroke patients [4].

Health-related quality of life should include dimensions of physical dimension, functional dimension, psychological dimension and social dimension [4]. This study looked at four dimensions of health-related quality of life [5], as follows:

\section{Physical Dimensions}

This dimension refers to disease-related and treatment-related symptoms [4]. According to the National Institute of Neurological Disorders and Stroke (NINDS, 2003), the possible effects of stroke can be Paralysis, Cognitive function deficits, Language deficits, emotional deficits, and pain.

From the results of interviews with poststroke patients in this study, the majority said experiencing physical changes, from being able to become a disability. One of the experiences experienced by all informants is the inability to perform a post-stroke activity in the post-stroke days. post-stroke patients who are physically impaired lead to a health-related quality of life can be said to be low. The low quality of life of post-stroke patients in healthcare in this physical dimension is due to health not only because of the presence of disease caused by viral or bacterial infections but also because of a condition that causes physical changes. In the WHO definition, healthy is not only free from disease but also 
means physically, mentally and socially healthy. A healthy person will have a good quality of life, as well as a good quality of life, of course, will support health [5].

\section{Functional Dimension}

According to De Hann et study, this dimension consists of self-care, mon- ility, and levels of physical activity such as the capacity to play a role in family and work life [4]

Functional dimension in question is the physical role, where the optimal physical condition and perfect will affect the physical function. Say that quality of life is a global concept that emphasizes the dimensions of health status including finance, shelter, and occupation.

, with the concept of quality of life as the center of health promotion, quality of lifebased on three areas of human life which are an important dimension in human experience: Being, Belonging and Becoming. These three things occur due to the interaction between a person and his environment.

When viewed from the results of interviews with post-stroke patients, it can be concluded that all patients who become primary informants experience impaired function in life, such as doing daily activities: walking, searching and processing even consume food, bathe, dress and earn a living or work. ability in performing its daily functions as a living being is very dependent on physical condition. If the physical condition is disturbed then the physical function is also disrupted. Emphasizes the basic aspect of who humans are as individuals. Physical being emphasizes on physical health and agility in performing activities [6].

The obstacles that occur in the average stroke patient are in mobility, where the mobility of the individual is performed on the basis of the individual's role. If the individual is his role as the head of the family who earns a living for the family, then the mobility done by the previous patient is as a worker who earns a living. But it depends on what type of work the patient is suffering from. Therefore, in post-stroke patients obstacles must occur in the role of patients in their lives, thus affecting the functional dimensions [6].

\section{Psychological Dimensions}

These dimensions include cognitive, emotional status, and perceptions of health, life satisfaction, and happiness [4].

In post-stroke patients with various symptoms perceived after a stroke attack that alters all elements of the patient's personal life, it affects the patient's psychological condition. disorders commonly experienced by poststroke patients can be physical and functional disorders such as loss of ability to move and walk, communicate and other disorders. Physical and functional disorders experienced by post-stroke patients if prolonged will result in a disturbance of psychological responses, as described by in his research where his research results show that post-stroke patients have long-term physical and functional disabilities will cause psychological disturbances that affect the quality of his life[1]. 
Feelings of distress can be interpreted as the psychological pressure felt by the patient due to the disruption felt by the patient after a stroke, especially for a long time. Many factors influence psychological pressure in post-stroke patients, that psychological problems greatly affect the quality of life of patients after a stroke. The psychological problems felt by most post-stroke patients are depression, dyspnoea, and psychological fatigue or helplessness [1]

Psychologically felt by post-stroke patients can be compressed by the support of the family and the process of acceptance of the current condition by the patient as well as the rapid treatment process, appropriately both to accelerate the improvement of the condition. Writes that couples of stroke patients often play a role as Primary Caregiver while the child of the patient is more of a Secondary Caregiver Messecar in Cempaka [7]. Primary Caregiver is the individual responsible for most direct parenting tasks, including emotional support, while Secondary Caregiver or the reserve nanny in charge of supporting and assisting the primary caregiver's role directly and indirectly. Rehabilitation therapy is one of the factors that also affect the quality of life-related to health in stroke patients [4].

Psychological disturbances felt by patients with post-stroke patients has not been meaningful because of family support either wife or husband as Primary Caregiver and child as Secondary Caregiver to the patient, for example in fulfilling the needs of the days and finance. Other factors that cause psychological disturbance are not meant to be felt by the patient in this study also because the treatment or rehabilitation goes well.

Stroke attacks will lead to post-stroke patients having psychological problems in cognitive matters. This suggests that brain damage due to stroke affects the patient's way of thinking, but this can be tackled through the family's role in nurturing and maintaining poststroke patients. So that the role of the couple as Primary Caregiver and children as Secondary Caregiver in receiving and controlling cognitive disorder patients greatly affect the reduction of psychological disorders patients post-stroke.

\section{Social Dimension}

According to De Hann et al. The social dimension includes the assessment of aspects of contact and social interaction both qualitatively and quantitatively [4]

The interactions that many find by poststroke patients come from families. The family is the closest to the patient, especially couples. However, a patient also needs to interact with others either friends or neighbors around. Of the four post-stroke patients who became the primary informants of this study revealed that the interaction during this after stroke is with family and neighbors around the house.

Social interaction is one of the basic human needs. The interaction required by a post-stroke patient is as a social support gained by the patient. Social support can be obtained from family and others. Classifies aspects of 
social support in four classifications: (1) Economic aspects, (2) Aspects of Appreciation, (3) Information Aspects, (4) Instrumental Aspect [8]. All these aspects are needed by the patient in living his life after a stroke attack. States that social support as social interaction or social relationships that provide tangible assistance or compassion to individuals or groups directed by the concerned, love. Some of the most widely accepted sources of social support by poststroke patients who became informants in the study were family and medical team [8].

Social support will actually affect the psychological sufferers of stroke. Therefore, social interaction and support are needed by post-stroke patients. The necessary social support can be in the form of appreciation, empathy, love, being listened to, kind attention in the form of advice or advice from people around. Support from people other than families such as medical TEAM who provide patient care is also necessary, especially regarding health information.

Attention and caring for the patient by the family, not just how the family meets the patient's daily needs but also how the patient is valued as if he/she is not a sick person.

Family support is also needed by the patient to be able to accept his condition and not feel the psychological pressure on the changes that occur. For example by talking even if the sentence is not easy to understand or invite out the house despite the difficulty in the activity. Things like this are actually needed by patients post-stroke. Stroke has an impact that can affect a person's activities, such as making a person not confident, reduce productivity, loss of spirit to carry out hobbies and many others. In improving the confidence of a patient

post-stroke is expected the role of the family and people around to accept the patient's condition and still appreciate and want to empathize with the patient.

\section{b. Nursing Care and Family Role in Patients}

\section{Post-stroke}

The support of medical personnel ie doctors in providing treatment to patients poststroke is needed because doctors based on their knowledge know what should be done and given to patients in improving the condition of post-stroke patients. The rest of the action outside of treatment usually doctors will carry out collaboration with other medical teams either nurse, nutritionist, laboratory or expert therapy and others. The purpose of this collaboration is to maximize the recovery of the conditions according to the discipline of each medical team.

Nursing care is in the form of assistance provided to clients from the healthy range to face hajal even the process of mourning. In patients who have occurred a disorder or disease, assistance is given in an effort to speed up the healing process, prevent disease does not grow and worsen and prevent the consequences caused by the disease either in the form of physical or psychological complications ${ }^{(\mathbf{1})}$. The nursing care in patients 
post-stroke attacks include (1) Assessment: Physical status, psychosocial status; (2) Nursing Diagnosis; (3) Nursing Intervention; (4) Evaluation of results.

According to informants as nurses at Poly Saraf RSUD Ulin Banjarmasin who become, Information Triangulation in this research states that the activities that are performed on post-stroke patients who undergo outpatient are Assessment, establish nursing diagnoses, provide nursing intervention and evaluate the results and all recorded in patient status. but the focus of problem-solving done by nurses in nursing care is to provide counseling for optimum patient care at home.

Nursing care provided by nurses to patients and families of post-stroke patients who are the subject of this study can be concluded that the nursing care provided is enough to give a positive impact as discussed above (quality of life of patients post stroke). The role of the family is optimal enough in providing care to patients although not perfect.

The effectiveness of nursing care provided by the nurses has an effect on the proper upbringing by the family as Caregiver at home. Optimally nursing care is also not separated from the role of the entire medical team in providing motivation to patients and families.

\section{c. Family role in post-stroke patients}

The role of the family is very important for post-stroke patients because the family is the closest person and the person who is able to help fulfill the daily needs of the patient.
Limitations or physical and functional disorders in post-stroke patients are a problem or impact of a stroke, such as a disruption in the fulfillment of day-to-day activities of bathing, eating, dressing and walking. therefore, the role of the nearest person to help overcome such impacts is necessary. As discussed in the discussion of Post-Stroke Patient Quality of Life above, The couple from stroke patients often play a role as Primary Caregiver while the child of the patient more acts as Secondary Caregiver [7]. Primary Caregiver is the individual responsible for most direct parenting tasks, including emotional support, while Secondary Caregiver or the reserve nanny in charge of supporting and assisting the primary caregiver's role directly and indirectly.

Family activeness, awareness, and patience as a caregiver for post-stroke patients is a key factor in their success in providing appropriate care to stroke-affected families. Post-Stroke Patients are patients who require full family attention related to the impact of a stroke.

\section{CONCLUSION}

Based on the findings of this study, the following conclusions are obtained Poststroke, there are limitations of daily activities of participants (patients who become the main. informant). The limitations of this activity are supported by the many phrases from the study participants saying that after a stroke attack can not scatter, as usual, talk a bit difficult and hard to concentrate and already angry. 
Post-stroke patients who become participants (primary informants) have a low quality of life seen from the Physical, Functional, Psychological, Social Dimension. But the most influencing dimension is the Physical and Functional dimension. In poststroke patients who become study participants (primary informants) in this study did not have a significant interruption in the psychological dimension, this is because the support of the family in paying attention to the needs and view the patient as a family so that patients feel loved, valued and noticed though cognitive disorders in relation to the psychological dimension is still a problem.

The social dimension is not a significant problem because of the support of the family, and the people around both the medical team. In this case, the social support of the family, the people around the patient, the medical team is very good, it's just family attention in making the patient as a family that needs to be considered its existence needs to be considered again. Family concerns such as inviting patients to activities outside the home, for example, recreation or streets, although patients have limitations. Social and psychological dimensions are not a significant problem for post-stroke patients in this study. One of the factors is due to the optimal role of the family as a caregiver in providing home care. Implementation of this perna also cannot be separated from the role of medical teams in providing information, especially from Nurses in providing care Nursing.
Nursing care provided by the nurses to patients and families is by providing health counseling how to care for home patients based on the results of the assessment each time the patient and family come to the neurological center to perform ambulatory care. The role of the family is very important in improving the quality of life of post-stroke patients. In enhancing the role of the family it is necessary for the Medical Team's role whether doctors or nurses about information about proper care of the patient at home. This information would be better if delivered to both the patient and the family. The goal is a maximlanya family role as Primary Caregiver and Secondary Caregiver.

\section{REFERENCES}

[1]. Kariasa. I.M. Patient Perceptions Post Stroke Attacks on Their Quality of Life in Perspective of Nursing Care. Thesis. Register Nursing Specialties Medical Nursing Surgical Postgraduate Program Faculty of Nursing: University of Indonesia. 2009.

[2]. The mood. I.M. Patient Perceptions Post Stroke Attacks on Their Quality of Life in Perspective of Nursing Care. Thesis. Register Nursing Specialties Medical Nursing Surgical Post-Graduate Program Faculty of Nursing: University of Indonesia. 2009.

[3]. Rahayu, U.B. Improve Quality of PostStroke Life through Brain Activation. https://publikasiilmiah.ums.ac.id/bitstream /handle/11617/3365/MATERI\%20BU\%20 UMI.pdf?sequence=1. 2013.

[4]. Yani, Fitri I.A. Differences in Healthrelated Quality of Life Quality Among Ischemic Stroke Patients First and Repeated Attacks. Essay. Faculty of 
Medicine: Sebelas Maret University Surakarta. 2010.

[5].Harmaini. F. Test of Reliability and Validity of the European Quality Of Life 5 Dimension (EQ-5D) Form for Measuring the Quality of Health-Related Life at Elderly at RSUPNCM. Thesis. Postgraduate Faculty: University of Indonesia. 2006.

[6]. Handayani, D. Y. Life Quality Analysis of Patients and Families Post Stroke Attack (With Time Symptom). 2009.

[7].Ayuningputri .N \& Herdiyan. M. Perception Will Pressure on Psychological Welfare on Spouses with Stroke. Journal of Research and Measurement of Psychology, Vol. 2, No.2, Pg. 118-124. 2013.

[8].Hasan, N. \& Rufaidah, E.R. The Relationship between Social Support and Coping Strategies for Stroke Sufferers Dr. Moewardi Surakarta. Talents of Psychology, 2 (1): 41-62. 2013.

[9]. Bredle, M. J. Spiritual Well-Being as a Component of Health-Related Quality of Life: The Functional Assessment of Chronic Illness Therapy-Spiritual WellBeing Scale (FACIT-Sp). www.mdpi.com/journal/religions. 2012. 